\title{
Novel strategies of hypertension management in chronic kidney disease
}

Jacek Rysz¹ ${ }^{1}$ Maciej Banach², Beata Franczyk ${ }^{1}$, Anna Gluba-Brzózka ${ }^{3}$

\author{
${ }^{1}$ Department of Nephrology, Hypertension, and Family Medicine, Medical University \\ of Lodz, Lodz, Poland \\ 2Department of Hypertension, Medical University of Lodz, Lodz, Poland \\ ${ }^{3}$ Department of Nephrology, Hypertension, and Family Medicine, WAM Teaching \\ Hospital, Lodz, Poland
}

Submitted: 14 September 2018

Accepted: 14 January 2019

Arch Med Sci

DOI: https://doi.org/10.5114/aoms.2019.88020

Copyright $\odot 2020$ Termedia \& Banach

\begin{abstract}
Hypertension is the most frequent comorbidity affecting patients with chronic kidney disease. It causes functional and structural changes in the kidney. According to the results of the Chronic Renal Insufficiency Cohort (CRIC) study, $67 \%$ to $92 \%$ of patients with chronic kidney disease (CKD) suffer from hypertension, with increasing prevalence as kidney function declines. Hypertension is a complex polygenic disorder the occurrence of which depends on the interaction of the effects of many genes or gene combinations as well environmental factors. This review presents novel recommendations concerning hypertension treatment of chronic kidney disease patients, including ACE inhibitor (in order to slow down kidney disease progression), angiotensin II receptor blocker therapy, bumetanide, furosemide, calcium antagonist, etc. Moreover, non-pharmacological interventions aiming at reducing blood pressure, such as diet and life-style change and renal denervation, are described herein. Finally, we presented novel, emerging strategies including neprilysin and sacubitril/valsartan (LCZ696).
\end{abstract}

Key words: hypertension, chronic kidney disease, treatment, recommendations, renal denervation, novel strategies.

\section{Introduction}

Hypertension is the most frequent comorbidity affecting patients with chronic kidney disease (CKD). It causes functional and structural changes in the kidney [1]. According to the results of the Chronic Renal Insufficiency Cohort (CRIC) study, $67 \%$ to $92 \%$ of patients with CKD suffer from hypertension, with increasing prevalence as kidney function declines [2]. Hypertension may be the result of kidney disease, but on the other hand its presence can also accelerate progressive renal failure [3]. Due to the fact that renal disease progression and blood pressure (BP) elevation are closely related to each other, appropriate treatment is required not only to reduce cardiovascular risk, but also to prevent further kidney functional decline [4-6]. Hypertension significantly contributes to the development of heart failure (HF) and cardiovascular disease (CAD) [7].

The updated 2017ACC/AHA/AAPA/ABC/ACPM/AGS/APhA/ASH/ASPC/ NMA/PCNA Guideline for the Prevention, Detection, Evaluation, and Management of High Blood Pressure in Adults classifies hypertension as systolic

\author{
Corresponding author: \\ Jacek Rysz \\ Department of Nephrology, \\ Hypertension, and \\ Family Medicine \\ Medical University of Lodz \\ 113 Zeromskiego St \\ Lodz, Poland \\ E-mail: \\ jacek.rysz@umed.lodz.pl
}


blood pressure (SBP) value equal to $130 / 80 \mathrm{~mm} \mathrm{Hg}$ or higher [3]. In this guideline, SBP is categorised on the basis of average BP measured in a healthcare setting (office pressures) into four levels: normal (SBP < $120 \mathrm{~mm} \mathrm{Hg}$ and DBP $<80 \mathrm{~mm} \mathrm{Hg}$ ), elevated (SBP 120-129 mm Hg and diastolic blood pressure (DBP) < $80 \mathrm{~mm} \mathrm{Hg}$ ), or stage 1 (SBP 130-139 mm $\mathrm{Hg}$ or DBP $80-89 \mathrm{~mm} \mathrm{Hg}$ ) and stage 2 hypertension (SBP $\geq 140 \mathrm{~mm} \mathrm{Hg}$ or $\geq 90 \mathrm{~mm} \mathrm{Hg}$ ). Hypertensive urgency occurs when SBP >180 $\mathrm{mm} \mathrm{Hg}$ and/or DBP $>120 \mathrm{~mm} \mathrm{Hg}$, while hypertensive emergency is diagnosed when SBP $>180 \mathrm{~mm} \mathrm{Hg}$ plus target organ damage and/or DBP > $120 \mathrm{~mm} \mathrm{Hg}$ plus target organ damage.

Also, the Japanese Society of Hypertension (JSH 2014) [8] and the Japanese Society of Nephrology (JSN 2013) [9] guidelines recommend < 130/ $80 \mathrm{~mm} \mathrm{Hg}$ as a BP target in hypertensive CKD patients with diabetes mellitus or proteinuria and drug acting on renin-angiotensin system (RAS) as the first-choice antihypertensive agent [10]. However, in those with neither diabetes mellitus nor proteinuria, the target BP is $<140 / 90 \mathrm{~mm} \mathrm{Hg}$ and the first-line choices are: calcium channel blocker, RAS inhibitor, or diuretic $[4,8,9]$.

In the case of patients with untreated SBP higher than $130 \mathrm{~mm} \mathrm{Hg}$ but less than $160 \mathrm{~mm} \mathrm{Hg}$ or DBP greater than $80 \mathrm{~mm} \mathrm{Hg}$ but less than $100 \mathrm{~mm} \mathrm{Hg}$, either daytime ambulatory blood pressure monitoring (ABPM) or home blood pressure monitoring (HBPM) should be used before the diagnosis of hypertension in order to screen for the presence of white coat hypertension [3].

The Report of the American College of Cardiology/American Heart Association Task Force on Clinical Practice Guidelines also provides new treatment recommendations, which include lifestyle changes as well as BP-lowering medications [3].

\section{Causes of hypertension}

Hypertension is a complex polygenic disorder the occurrence of which depends on the interaction of the effects of many genes or gene combinations as well as environmental factors [11]. Liddle's syndrome, Gordon's syndrome, and glucocorticoid-remediable aldosteronism are rare forms of monogenic hypertension [12]. Moreover, over 25 rare mutations and 120 single nucleotide polymorphisms contributing to BP and hypertension have been identified $[12,13]$. However, according to studies, the collective effect of all determined $\mathrm{BP}$ loci accounts for only about $3.5 \%$ of BP variability [13]. According to Ference et al. [14] the occurrence of numerous small-effect alleles that results in increased BP levels is associated with a more rapid rise in $\mathrm{BP}$ with age.

Apart from genetic factors, also environmental agents, including diet, physical activity, and alco- hol consumption influence blood pressure levels [3]. Many diet-related factors have been demonstrated to be associated with high BP levels. Overweight or obesity, excessive intake of sodium and alcohol, low consumption of magnesium, potassium, calcium, fibres, and fish fats in combination with low physical activity are responsible for hypertension in many individuals $[15,16]$. Large epidemiological studies, such as the Framingham Heart Study [17] and the Nurses' Health Study [18], have confirmed a direct, continuous, and almost linear relationship between body mass index and BP [19]. In these studies, obesity was suggested to be responsible for about $40 \%$ or $78 \%$ of hypertension in men and $65 \%$ in women, respectively $[20,21]$. Numerous studies also demonstrated a positive association between sodium intake and age-related increase in BP $[22,23]$. Certain groups, including the black population, older adults, and those with a higher level of BP or comorbidities such as CKD, diabetes mellitus (DM), or metabolic syndrome, are particularly sensitive to the impact of dietary sodium on BP [24-26]. However, higher level of potassium was suggested to blunt the effect of sodium on BP [27]. Individuals with lower sodium-potassium ratio have been demonstrated to have lower levels of BP in comparison to those with similar levels of sodium or potassium [28].

The inverse association between physical activity/physical fitness and BP level and hypertension has been proven in epidemiological studies [29]. Even modest levels of physical activity have been found to diminish the risk of incident hypertension [30, 31], attenuate the rise of BP with age, and prevent the development of hypertension. The contribution of alcohol intake to the prevalence of hypertension varies in relation to the level of its consumption [32].

Sudden onset of hypertension, severe elevation of BP, pharmacologically resistant hypertension, and increased BP in patients with hypertension previously controlled on drug therapy may have a specific, remediable cause and is called secondary hypertension. According to estimates it can be identified in approximately $10 \%$ of adult patients with hypertension. The most frequent causes of secondary hypertension include the following: renovascular disease (5-34\%), obstructive sleep apnoea (25-50\%), primary aldosteronism (8-20\%), drug or alcohol induced (2-4\%) and renal parenchymal disease (1-2\%), and hyperthyroidism [3, 33-35].

The prevalence of hypertension is increasing worldwide. A large multi-centre national population health examination survey (WOBASZ) demonstrated that the occurrence of hypertension in Poland is high and increased by about $12 \%$ in 10 years [36]. 


\section{Treatment of CKD patients - novel recommendations}

The most recent 2018 ESC/ESH guidelines for the management of arterial hypertension suggest that in patients with diabetic or non-diabetic CKD the recommended office blood pressure should be $\leq 140 / 90 \mathrm{~mm} \mathrm{Hg}$ along with lifestyle advice and BP-lowering medication (Class I, Level A) [37]. Moreover, in this group of patients, SBP should be lowered to within the range 130-139 mm Hg (Class I, Level A). According to this recommendation, individualised treatment should be applied in reference to its tolerability and impact on renal function and electrolytes (Class Ila, Level C). Initial therapy was suggested to comprise a combination of RAS blocker (which is most effective at reducing albuminuria) with a calcium-channel blockers (CCB) or a diuretic (Class I, Level A). Loop diuretics are much more effective than thiazide/ thiazide-like diuretics when eGFR is reduced to $<30 \mathrm{ml} / \mathrm{min} / 1.72 \mathrm{~m}^{2}$. Finally, a combination of two RASs is not recommended (Class III, Level A) [37]. In the case of resistant hypertension, spironolactone (25-50 mg o.d.) or other diuretic, $\alpha$-blocker, or $\beta$-blocker should also be used. However, in patients with eGFR $<45 \mathrm{ml} / \mathrm{min} / 1.72 \mathrm{~m}^{2}$ or baseline $\mathrm{K}^{+} \geq 4.5 \mathrm{mmol} / \mathrm{l}$ spironolactone should be used with caution due to the risk of hyperkalaemia. Patients with CKD should also receive lifestyle advice on sodium restriction, and drug treatment when their office BP is >140/90 mm $\mathrm{Hg}$. Lifestyle advice seems to be especially effective at aiding BP lowering in patients with CKD. $\mathrm{BP}$ lowering reduces renal perfusion pressure, thus it is not unusual for eGFR to be reduced by 10-20\% in patients treated for hypertension [37]. Careful monitoring of blood electrolytes and eGFR is essential in these patients; however, clinicians should not be alarmed by the anticipated decline in GFR, which usually occurs within the first few weeks of treatment and stabilises thereafter. The treatment should be stopped if the decline in GFR continues or becomes more severe. At that time the patient should be examined for the presence of renovascular disease [37].

\section{According to the updated 2017}

ACC/AHA/AAPA/ABC/ACPM/AGS/APhA/ASH/ ASPC/NMA/PCNA guidelines in adults with hypertension and CKD, the BP goal that should be reached is < 130/80 $\mathrm{mm} \mathrm{Hg}$ [3, 38-42]. CKD is an important risk factor for cardiovascular disease, and its coexistence with hypertension further increases this risk as well as cerebrovascular event risk, especially in the presence of proteinuria [43]. There are very few data supporting BP targets in CKD, due to the fact that patients with CKD are usually excluded from clinical trials. In the past, most recommendations concerning BP targets in patients with CKD favoured BP < 140/90 mm Hg [44], except for the case of patients with more severe proteinuria ( $\geq 300 \mathrm{mg}$ albuminuria in $24 \mathrm{~h}$ or the equivalent) in whom the lower target of $<130 / 80 \mathrm{~mm} \mathrm{Hg}$ was established [45-47]. The results of the SPRINT study, which enrolled also patients with advanced CKD, favoured a lower target of $<130 / 80 \mathrm{~mm} \mathrm{Hg}$ for all patients with CKD [48]. However, some observational studies of CKD patients demonstrated a higher risk of mortality at lower systolic pressures in elderly patients with CKD $[49,50]$. This suggests that complex patients may be at greater risk of complications associated with intense BP treatment, even those who failed to achieve lower BP targets.

In hypertensive patients with chronic kidney disease, combining two or more antihypertensive agents is frequently necessary in order to achieve the current BP goal [51]. However, according to studies, in hypertensive CKD patients, BP control is not achieved even in many patients taking three antihypertensive agents [52]. The reasons for that may include the following: salt and water retention, enhanced sympathetic nervous system activity, increased activity of RAS, and reduced biological activity of nitric oxide systems [4, 53-56]. Despite the use of antihypertensive medications, the aforementioned mechanisms compensate each other to make BP control difficult. Therefore, there is a need for new efficient antihypertensive agents that will be not only safe for CKD patients but also will slow the progression of renal disease.

Adults with hypertension and CKD stage 3 or higher or stage 1 or 2 with albuminuria $\geq 300 \mathrm{mg} /$ day, or $\geq 300 \mathrm{mg} / \mathrm{g}$ albumin-to-creatinine ratio or the equivalent in the first morning void, should be treated with an angiotensin converting enzyme (ACE) inhibitor in order to slow down kidney disease progression [39, 57-59]. In adult patients with hypertension and CKD stage 3 or higher or stage 1 or 2 with albuminuria $\geq 300 \mathrm{mg} /$ day, or $\geq 300 \mathrm{mg} / \mathrm{g}$ albumin-to-creatinine ratio in the first morning void, who do not tolerate ACE inhibitors, treatment with an ARB may be reasonable [57]. A $10 \%$ to $25 \%$ rise in serum creatinine may occur in some patients with CKD as a result of either ACE inhibitor or ARB therapy [60].

In the treatment of hypertensive patients with or without CKD, combinations of drugs that have similar mechanisms of action or clinical effects should be avoided due to the fact that agents targeting the same BP control system are less effective and are potentially harmful when used together [3]. Large studies and trials indicate increased cardiovascular and renal risk following simultaneous use of RAS blockers $[60,61]$. The combination 
of an ACE inhibitor and an angiotensin receptor blockers (ARB) should be avoided because it is associated with harm observed in several large cardiology trials [60]. Also, the combination of an ARB (or ACE inhibitor) and a direct renin inhibitor is contraindicated in CKD patients due to the enhanced risk of hyperkalaemia and hypotension and lack of confirmed benefit [62]. $\beta$-blockers are not recommended as first-line drugs, except for patients suffering from ischaemic heart disease (IHD) or heart failure (HF) [3].

In CKD patients, the risk of hyperkalaemia is increased while using ACE inhibitors (Benazepril, Captopril, Enalapril, Fosinopril, Lisinopril, Moexipril, Perindopril, Quinapril, Ramipril, Trandolapril), ARBs (Azilsartan, Candesartan, Eprosartan, Irbesartan, Losartan, Olmesartan, Telmisartan, Valsar$\tan )$, or direct renin inhibitor (Aliskiren). Moreover, in cases of patients with severe bilateral renal artery stenosis, there is a risk of acute renal failure following the administration of ACE inhibitors, ARBs, or direct renin inhibitor (Aliskiren) [3].

Some studies demonstrated that valsartan was well tolerated and effective in treating patients with hypertension and CKD [4].

In chronic kidney disease, the interplay between levels of extracellular fluid (ECF) volume expansion and treatment of CKD-related hypertension is of importance [51]. Volume-dependent hypertension is more frequent in CKD patients, and therefore diuretics often need to be included in the antihypertensive management. High doses of diuretics, despite being very effective in reducing BP, are also associated with metabolic complications, such as hypokalaemia [51].

In patients with moderate-to-severe CKD (GFR $<30 \mathrm{ml} / \mathrm{min}$ ), bumetanide, furosemide, and torsemide are preferred over thiazides [3]. Diuretics, such as amiloride and triamterene, should be avoided in patients with significant CKD (e.g. GFR $<45 \mathrm{ml} / \mathrm{min}$ ).

Calcium antagonists (CAs), which are frequently used in patients with CKD and hypertension, do not have to be dose-adjusted in this group of patients $[51,63]$. CAs comprise dihydropyridines and non-dihydropyridines which have similar antihypertensive efficacy but a different impact on proteinuria and progression of kidney function [51]. According to studies, the administration of non-dihydropyridine CAs (verapamil, diltiazem) to patients with overt nephropathy was associated with diminished proteinuria and a lower rate of clearance decline [64] while dihydropyridine CAs exerted a similar effect only after the simultaneous use with RAAS blocker [65]. Therefore, dihydropyridine CAs should not be used as monotherapy in diabetic or non-diabetic kidney disease with proteinuria, but always in combination with an ACE inhibitor or an ARB $[51,66]$. The Avoiding Cardiovascular Events through Combination Therapy in Patients Living with Systolic Hypertension (ACCOMPLISH) study [67] demonstrated the CV risk-lowering efficacy of CA agents when paired with an ACE inhibitor.

Renin inhibitors (e.g. aliskiren), which bind to the renin molecule and limit its catalytic activity, are responsible for reduced plasma renin activity, and Ang I and Ang II levels [51, 68]. Aliskiren, apart from being efficacious in controlling BP in monotherapy, has also been demonstrated to decrease albuminuria, lower BP, normalise serum creatinine, inhibit atherosclerosis development, and improve plaque stability in animal models $[69,70]$. Large trials, including the Aliskiren in the Evaluation of proteinuria in Diabetes (AVOID) trial [71] and the Aliskiren Observation of Heart Failure Treatment (ALOFT) trial [72] also revealed the reduction of urine albumin to creatinine ratio (UACR) and neurohumoral suppression in heart failure.

It has been demonstrated that alterations in the endothelin 1 (ET-1) system presents in patients with kidney disease coexisting with cardiovascular disorders, hypertension, and endothelial dysfunction [51]. ET-1 has been suggested to play an important role in the development of hypertension, cardiovascular hypertrophy, renal fibrosis, and glomerulosclerosis [51, 73]. Therefore, its antagonists have been analysed as potential anti-hypertensive and renal impairment rate-slowing medications. Goddard et al. [73] revealed that ET-1 antagonist was highly effective in lowering $\mathrm{BP}$ and reducing proteinuria in CKD patients. The study of healthy persons demonstrated that ET-1 receptor blockade improved renal blood flow and increased natriuresis, but only when it was used in combination with an ACE inhibitor [74]. Moreover, two randomised controlled trials of selective ET-1 antagonists (danusertan [75] or avosentan [76]) showed that these agents were effective and could be used in high-risk patients with resistant hypertension, and that the latter reduced UAER in a dose-dependent manner, independently of BP.

Before the initiation of treatment, atherosclerotic cardiovascular disease (ASCVD) risk should be assessed in hypertensive CKD patients [1]. If the 10 -year ASCVD risk is $\geq 10 \%$, they are in a high-risk group and they require antihypertensive therapy with a BP target $\geq 130 / 80 \mathrm{~mm} \mathrm{Hg}$. Recent meta-analyses and systematic reviews including patients with CKD from the SPRINT study confirm that more intensive BP treatment [77-79] reduces the frequency of CAD events but failed to demonstrate a reduction in the rate of progression of kidney disease. Also, a BP-Lowering Treatment Trialists' Collaboration meta-analysis of RCTs enrolling patients with CKD revealed bene- 
Table I. Comparison of blood pressure treatment guidelines in chronic kidney disese (CKD) patients

\begin{tabular}{|c|c|c|}
\hline Guideline & Target blood pressure $[\mathrm{mm} \mathrm{Hg}]$ & Initial drug therapy \\
\hline $\begin{array}{l}\text { ESC/ESH } 2018[78] \\
18-65 \text { years } \\
65-79 \text { years } \\
\geq 80 \text { years }\end{array}$ & $\begin{array}{l}<140 \text { to } 130 / 70-79 \text { (if tolerated) } \\
130-139 / 70-79 \text { (if tolerated) } \\
130-139 / 70-79 \text { (if tolerated) }\end{array}$ & $\begin{array}{c}\text { ACE inhibitor or ARB + CCB or } \\
\text { ACE inhibitor or ARB + diuretic (loop diuretic) }\end{array}$ \\
\hline $\begin{array}{l}\text { Hypertension } \\
\text { Canada (2018) [78] }\end{array}$ & $<140 / 90$ & With proteinuria: ACE inhibitor or ARB \\
\hline ACC/AHA (2017) [3] & $<130 / 80$ & $\begin{array}{l}\text { Thiazide, CCB, ACE inhibitor, or ARB } \\
\text { With proteinuria: ACE inhibitor or ARB }\end{array}$ \\
\hline JNC 8 (2014) [42] & $<140 / 90$ & ACE inhibitor or ARB \\
\hline ASH/ISH (2014) [79] & $<140 / 90$ & ACE inhibitor or ARB \\
\hline ESH/ESC (2013) [80] & $<140 / 90$ & $\begin{array}{l}\text { Thiazide, CCB, } \beta \text {-blocker, ACE inhibitor, } \\
\text { With proteinuria: ACE inhibitor or ARB }\end{array}$ \\
\hline $\begin{array}{l}\text { KDIGO (2012) [45] } \\
\text { CKD with albuminuria } \\
\geq 30 \mathrm{mg} / 24 \mathrm{~h} \text { or equivalent }\end{array}$ & $\leq 130 / 80$ & ACE inhibitor or ARB \\
\hline $\begin{array}{l}\text { KDIGO (2012) [45] } \\
\text { CKD with albuminuria } \\
<30 \mathrm{mg} / 24 \mathrm{~h} \text { or equivalent }\end{array}$ & $\leq 140 / 90$ & ACE inhibitor or ARB \\
\hline NICE (2011) [81] & $<140 / 90$ & Patients with proteinuria: $A C E$ inhibitor or $A R B$ \\
\hline JNC 7 (2003) [82] & $<130 / 80$ & ACE inhibitor or ARB \\
\hline
\end{tabular}

$A C E$ inhibitor - angiotensin-converting enzyme inhibitor, $A R B$ - angiotensin receptor blocker, $C C B$ - calcium channel blocker.

fits of more intensive BP lowering [48]. Moreover, before the treatment, the physician must consider many important factors including salt intake, proteinuria levels, the need for RAAS blockade, as well as adherence to prescribed therapies [51] (Table I) $[3,42,45,78-82]$.

\section{Non-pharmacological interventions reducing blood pressure}

Updated 2017 ACC/AHA/AAPA/ABC/ACPM/AGS/ APhA/ASH/ASPC/NMA/PCNA Guidelines for the Prevention, Detection, Evaluation, and Management of High Blood Pressure in Adults recommend weight loss as a measure to reduce BP in overweight or obese adults with elevated BP or hypertension (recommendation class IA) [3]. The results of a meta-analysis of randomised controlled trials suggest that a $1 \mathrm{~mm} \mathrm{Hg}$ drop should be expected following at least a $1 \mathrm{~kg}$ reduction in body weight in the case of most overweight people.

\section{Diet and life-style change}

Individuals with elevated BP or hypertension should switch to a heart-healthy diet, such as the dietary approaches to stop hypertension (DASH) diet (recommendation class IA) and should reduce sodium consumption (recommendation class IA) [3]. The DASH diet, which is rich in fruit, vegetables, low-fat dairy products, whole grains, lean meats, fish, poultry, nuts, seeds, and legumes, with reduced sweets and saturated fat, substantially reduces blood pressure [83-86]. According to studies, the addition of sodium diminishing to the DASH diet further decreases blood pressure and reduces the risk of hypertension, cardiovascular disease, stroke, and mortality [87, 88]. A study by Tyson et al. [89] indicated that reduced saltDASH diet considerably enhanced the percentage nocturnal BP decline (nocturnal hypertension is strongly associated with death and/or cardiovascular events), and therefore it may be beneficial in moderate CKD. The results of a large study of 14,882 middle-aged African-American and Caucasian men and women suggested that a low-sodium DASH-style diet was also associated with lower risk of kidney disease [90]. High dietary sodium is an important factor affecting blood pressure, which predisposes patients with established CKD to salt-sensitive hypertension and fluid retention [86, 91]. Moreover, it is also directly associated with renal damage. The results of studies performed on animal models indicated salt-induced kidney damage, which confirms that high salt intake aggravates renal damage. Also, such alternative methods as application of standardised tomato extract (STE) may prove beneficial in hypertensive, obese patients due to its antiplatelet effect [92].

Hypertensive patients or those with increased BP levels also ought to take up or increase physical activity suitable for persons with elevated BP or hypertension and cut down on excessive alcohol consumption (if applicable). Prospective studies have demonstrated a beneficial impact of moderate physical activity on the management of 
HTN [93]. Moreover, Diaz et al. [94] revealed moderate-vigorous physical activity reduced incident hypertension in African American adults by an estimated $24 \%$ (95\% confidence interval 1-42\%). Regular physical activity was demonstrated to reduce the blood pressure of individuals with hypertension. A review of the BP-lowering effect of aerobic physical activity in 27 randomised controlled studies on individuals with hypertension showed a reduction in $\mathrm{BP}$ by a mean of $11 / 5 \mathrm{~mm} \mathrm{Hg}$ following a regular medium-to-high-intensity aerobic activity [95]. Moreover, three randomised controlled trials (RCTs) concerning isometric (static) activity demonstrated similar magnitudes of $\mathrm{BP}$ reduction in hypertensives while five available RCTs revealed lower effects of dynamic resistance training [95]. Finally, Cavelaars et al. [96] found that the increase in physical activity from a very low level (e.g. watching television) to a moderate level (e.g. shopping) was associated with an average response ofSBP of $11.6 \mathrm{~mm} \mathrm{Hg}$, DBP of $7.0 \mathrm{~mm} \mathrm{Hg}$, as well as HR of 16.1 beats/min, and this effect was greater in the case of overweight subjects and increased with advancing age [96].

Stress reduction seems to be a promising tool of blood pressure lowering; however, it is difficult to assess its exact impact. The results of studies analysing the impact of behavioural therapies, such as guided breathing, yoga, and transcendental meditation, failed to provide final confirmation of their BP-lowering efficacy. Respiratory therapy is a not well-known form of lowering BP. The use of a portable electronic device called a RESPeRATE, which enables slow and deep breathing ("paced breathing"), was demonstrated in clinical trials to directly influence BP [97]. According to studies, slow breathing (<10 bpm), especially with prolonged exhalation, enhances baroreflex sensitivity (BRS) in hypertensive patients and reduces sympathetic nerve-influencing arteriolar dilatation. In patients with isolated systolic hypertension (ISH) systolic blood pressure was reduced by $18 \pm 7$ and $11 \pm 4 \mathrm{~mm}$ $\mathrm{Hg}$ in patients participating in slow-breathing training, with and without an inspiratory load, respectively $(p<0.001)$. Slow-breathing training, particularly with an inspiratory load, has been demonstrated to be highly effective in reducing resting systolic and pulse pressures.

Also the reduction of alcohol consumption is beneficial in the lowering of BP. A study by Wakabayashi [98] revealed a considerably higher SBP in men who were moderate and heavy drinkers, while the BP of women was significantly higher only in heavy drinkers compared with non-drinkers. Also, DBP was significantly higher in light, moderate, and heavy drinkers of both genders.

\section{Renal denervation (RDN)}

Renal denervation (RDN) is a different type of non-pharmacological methods to lower blood pressure [99]. This interventional procedure is based on the interruption of the efferent and afferent renal nerves, which travel together in the adventitia of the renal arteries [100]. The negative role of enhanced renal sympathetic activation in the development and progression of CKD is well established [101]. However, in the early stages of chronic renal failure, the sympathetic activity is elevated and the degree of sympathetic overdrive rises with disease progression. According to studies, both renal sympathetic efferent and afferent nerves exert a potent impact on the initiation, development, and maintenance of elevated systemic BP commonly present in patients with renal failure [101, 102]. Sympathetic overactivity is also an independent predictor of cardiovascular events and mortality in ESRD [102]. Afferent signalling within the native failing kidneys plays a contributory role in renal efferent sympathetic excitation and aggravates the adverse effect of chronically increased sympathetic drive [103]. Therefore, the interruption of efferent and afferent renal fibres possibly alleviates or reverses autonomic imbalance and diminishes renal sympathetic outflow and arterial BP in CKD [104]. The aim of renal denervation is to ablate the effects of augmented sympathetic drive to the kidney, which contributes to the development of hypertension in CKD patients mainly due to sympathetic activation and the release of renin [99]. The reduction of efferent renal nerve traffic also attenuates renal sodium reabsorption [100]. The decline in afferent renal nerve traffic to the brain diminishes central sympathetic outflow to the vasculature and the peripheral organs, including the heart and kidneys [100]. In humans, renal denervation, which is achieved by the delivery of radiofrequency or other forms of energy or norepinephrine-depleting pharmaceuticals via catheters located in the renal arteries, does not require general anaesthesia or surgical implantation of a device [100, 105, 106].

Two trials, SymplicityHTN-149 [107] and Symplicity HTN-250 [108], in which a minimally invasive catheter-based radiofrequency strategy was used to obtain renal nerve denervation, were very successful, and the reduction in blood pressure observed in them lasted for up to three years in many cases. However, the design of these studies was later questioned and the effects of renal denervation were again analysed in the large multi-centre, sham-controlled, blinded Symplicity HTN-3 trial [109]. In turn, this trial demonstrated no significant blood pressure reductions between the renal denervation and the sham groups after 6 months of follow-up. However, the randomised DENERHTN 
study indicated that in patients with resistant hypertension, despite using RAA system inhibitor, calcium antagonist, and thiazide diuretics, denervation is more effective than the addition of next hypotensive drugs, including spironolactone.

Clinical data in the field of renal denervation use in advanced chronic kidney disease patients are sparse, due to the fact that such patients have been excluded from most trials.

A study of renal denervation in a small group of patients with resistant hypertension and concomitant moderate-to-severe CKD (mean estimated glomerular filtration rate $31 \mathrm{ml} / \mathrm{min}$ per $1.73 \mathrm{~m}^{2}$ ) demonstrated remarkable reductions of in-office BP (-32/-15 and $-33 /-19 \mathrm{~mm} \mathrm{Hg}$ at 6 and 12 months of follow-up, respectively) [104]. This study demonstrated that selective, bilateral sympathetic renal denervation was safe and effective in patients with stage 3-4 CKD and was not associated with acute or short-term deterioration of renal function. Radiofrequency ablation treatment also had a substantial effect on nocturnal BP control, BP power surge, and night-to-day $B P$ ratios. Moreover, in the study of Hering et al. [104], renal denervation reduced mean and maximum night-time BP and restored a physiological dipping pattern in the majority of patients (9 out of 10 patients). The lowering of nocturnal BP is important, because its value predicts cardiovascular events better than 24-hour mean or diurnal BP $[104,110]$. Renal denervation was not associated with further deterioration of renal function in CKD patients. In this study also gradual increase in serum haemoglobin levels was observed in all treated patients [105], perhaps as a result of the role of renal sympathetic nerves in the modulation of erythropoiesis [111]. Moreover, a trend toward reduction of urinary albumin excretion, a trend toward reduction in plasma circulating BNP concentrations, and the improvement in augmentation index were observed after renal denervation [104]. According to Marchais et al. [112], higher augmentation index is associated with target-organ damage in haemodialysis patients. The preliminary results of Hering et al. [104] suggest that a wide range of high-risk patients with chronic renal failure and several comorbidities, such as resistant hypertension, diabetes, obesity, and obstructive sleep apnoea, may benefit from bilateral renal denervation.

Another safety and proof-of-concept study, in which renal denervation was performed in 12 patients with ESRD and uncontrolled BP, demonstrated significantly reduced (in comparison to baseline) office systolic BP at 3, 6, and 12 months after renal denervation (RDN) (from $166 \pm 16.0$ to 148 $\pm 11,150 \pm 14$, and $138 \pm 17 \mathrm{~mm} \mathrm{Hg}$, respectively) [113]. According to the authors, this procedure is reasonable in patients with end-stage renal disease (ESRD), and it results in a sustained reduction in systolic office BP. However, atrophic renal arteries may pose a problem for application of this technology in some patients with ESRD [114].

However, due to the small number of patients in these studies, there is a need for larger RCTs in this patient population.

\section{Novel, emerging strategies}

Neprilysin is an enzyme responsible for the breakdown of natriuretic peptides as well as the processing and catabolism of other vasoactive peptides, including bradykinin, substance $P$, angiotensin II, and endothelin $[99,113]$. Due to the fact that the inhibition of neprilysin raises natriuretic peptide levels, resulting in natriuresis, vasodilation, and functional inhibition of the RAS, it has long been considered a target for hypertension [113]. However, it was found that this enzyme also degrades peptides, such as endothelin-1 and Ang II, that are responsible for vasoconstriction. A strong anti-hypertensive effect was observed when omapatrilat (the combination of neprilysin and ACE inhibition) was used [115]. Omapatrilat not only considerably inhibited ACE, diminished levels of angiotensin II, and reduced systemic BP, but also markedly enhanced renal blood flow without associated changes in glomerular filtration rate (GFR) and decreased filtration fraction. The results obtained when the animal model of hypertension was used indicate that long-term administration of omapatrilat results in dose-dependent reductions in BP and proteinuria, and hampered progression of glomerulosclerosis, tubulointerstitial fibrosis, and renal injury [116]. In the OVERTURE trial of patients with New York Heart Association class II to IV heart failure, the worsening of renal impairment occurred less frequently with omapatrilat (6.8 vs. $10.1 \%$ with enalapril), even in those with moderate renal impairment (determined as serum creatinine < $221 \mu \mathrm{mol} / \mathrm{l}$ at baseline) [117]. Therefore, it was a very promising drug for patients with chronic kidney disease. However, due to the higher rate of angioedema observed in the large-scale heart failure trial Omapatrilat Cardiovascular Treatment versus Enalapril (OCTAVE), following the administration of omapatrilat, this therapeutic strategy has been discontinued [107, 117]. The Food and Drug Administration review board did not approve omapatrilat [118]. Currently, a novel combination of equal proportions of neprilysin inhibitor - sacubitril with AT1 receptor antagonist valsartan has been widely tested. The new drug, called LCZ696, does not inhibit bradykinin metabolism as it was in the case of ACE inhibitors. A randomised, double-blind, placebo-controlled, active comparator study of LCZ696 
demonstrated significantly greater blood pressure reduction in comparison to valsartan in patients with mild-to-moderate hypertension [119].

An eight-week, multi-centre, open-label, phase III study including a placebo run-in period of 25 weeks for treated patients (to wash out the effects of earlier antihypertensive agents) and 1-2 weeks for untreated patients and an eightweek treatment period with LCZ696 $100 \mathrm{mg}$, with an optional dose titration to 200 or $400 \mathrm{mg}$ based on the need to achieve BP control, demonstrated that in a Japanese population of patients with hypertension and moderate-to-severe renal dysfunction (eGFR $\geq 15$ and $<60 \mathrm{ml} / \mathrm{min} / 1.73 \mathrm{~m}^{2}$ ) LCZ696 was generally safe and well tolerated and its administration was associated with effective BP reduction without a decline in renal function [4]. No severe AEs or deaths were reported; however, $43.8 \%$ of patients reported at least one mild-severity AE. The treatment was not associated with clinically meaningful changes in creatinine, potassium, blood urea nitrogen, and eGFR. The observed geometric mean reduction in urinary albu$\mathrm{min} /$ creatinine ratio (UACR) was $15.1 \%$, and it was greater in patients with macroalbuminuria than in patients with normoalbuminuria or microalbuminuria. The mean reduction in mean sitting systolic blood pressure (msSBP) and mean sitting diastolic blood pressure (msDBP) was $20.5 \pm 11.3$ and 8.3 $\pm 6.3 \mathrm{~mm} \mathrm{Hg}$, respectively, from baseline to the week 8 endpoint. The most potent antihypertensive effect of LCZ696 was seen during the first 2 weeks of treatment; from week 2 till 4 there were incremental reductions in $\mathrm{msSBP}$ and $\mathrm{msDBP}$, and then it remained stable until the week 8 endpoint [4]. This trial demonstrated that LCZ696 preserves GFR by maintaining glomerular capillary pressure despite reductions in BP [4]. According to estimates, $\mathrm{BP}$ control is achieved by $13-37 \%$ of patients in Japan, Spain, the US, and Norway [4, 120-122]. In this multi-centre, open-label, phase III study, $50 \%$ of patients achieved msSBP $<130 \mathrm{~mm} \mathrm{Hg}$ at endpoint (it was $151.6 \mathrm{~mm} \mathrm{Hg}$ at the inclusion). Favourable antihypertensive effects associated with LCZ696 treatment of hypertensive patients with renal impairment in this study were independent of the degree of renal impairment. Therefore, it seems that hypertensive patients with renal impairment can be treated with the same dose and regimen used in hypertensive patients with normal renal function [4].

The most recent trial, UK HARP-III, was conducted to compare the effects of sacubitril/valsar$\tan$ (LCZ696) and irbesartan on measured glomerular filtration rate (mGFR), estimated glomerular filtration rate (eGFR), urine albumin : creatinine ratio (UACR), systolic and diastolic blood pressure, as well as tolerability and safety in patients with eGFR $\geq 20<60 \mathrm{ml} / \mathrm{min} / 1.73 \mathrm{~m}^{2}$, potassium $<5.5 \mathrm{mmol} / \mathrm{l}$, and no history of angioedema or other contraindication to sacubitril/valsartan or irbesartan [123]. The combination of sacubitril/ valsartan exerts actions the same as an angiotensin receptor blocker (valsartan) and prevents the breakdown of certain proteins in the blood (sacubitril), which might slow the progression of kidney damage and delay the need for dialysis and transplant and be beneficial for the heart and blood circulation. This trial demonstrated that the administration of sacubitril/valsartan in comparison to irbesartan was associated with a non-significant $9 \%(95 \% \mathrm{Cl}:-1$ to 18$)$ reduction in study average uACR, a 5.4 (3.4-7.4) $\mathrm{mm} \mathrm{Hg}$ reduction in study average systolic blood pressure, and a 2.1 (1.03.3) $\mathrm{mm} \mathrm{Hg}$ reduction in study average diastolic blood pressure. The rate of serious and non-serious adverse events was similar in both treatment groups: 61 (29.5\%) vs. 59 (28.5\%); rate ratio 1.07 (0.75-1.53) and $76(36.7 \%)$ vs. 58 (28.0\%); rate ratio 1.35 (0.96-1.90), respectively. Moreover, the occurrence of hyperkalaemia was similar in both groups $(p=0.10)$. Therapy with sacubitril/valsartan, in comparison to irbesartan, caused additional reductions in blood pressure and had no effect on kidney function over 1 year and did not increase albuminuria. No difference was observed in safety or tolerability between sacubitril/valsartan and irbesartan among patients with CKD [123].

Drugs that are administered to treat hypertension in CKD patients have not changed significantly in decades. In contrast to other areas of medicine, the progress in this field is rather limited. It may be due to the fact that hypertension in patients with CKD looks like a vicious circle. However, personalised medicine, the aim of which is to determine the right drug for the right patient at the right time, may lead to a huge breakthrough [124]. The new therapies should be targeted towards specific phenotypes rather than sticking to the old 'one-fits-all' approach [125-127].

\section{Conflict of interest}

The authors declare no conflict of interest

\section{References}

1. Weber MA, Schiffrin EL, White WB, et al. Clinical practice guidelines for the management of hypertension in the community a statement by the American Society of Hypertension and the International Society of Hypertension. J Hypertens 2014; 32: 3-15.

2. Muntner P, Anderson A, Charleston J, et al. Hypertension awareness, treatment, and control in adults with CKD: results from the Chronic Renal Insufficiency Cohort (CRIC) Study. Am J Kidney Dis 2010; 55: 441-51.

3. Whelton PK, Carey RM, Aronow WS, et al. 2017 ACC/ AHA/AAPA/ABC/ACPM/AGS/APhA/ASH/ASPC/NMA/ 
PCNA guideline for the prevention, detection, evaluation, and management of high blood pressure in adults: a report of the American College of Cardiology/American Heart Association Task Force on Clinical Practice Guidelines. Hypertension 2018; 71: 1269-324.

4. Ito S, Satoh M, Tamaki Y, et al. Safety and efficacy of LCZ696, a first-in-class angiotensin receptor neprilysin inhibitor, in Japanese patients with hypertension and renal dysfunction. Hypertens Res 2015; 38: 269-75.

5. Yano Y, Fujimoto S, Sato Y, et al. Association between prehypertension and chronic kidney disease in the Japanese general population. Kidney Int 2012; 81: 293-9.

6. Niklas A, Flotyńska A, Puch-Walczak A, et al.; WOBASZ II investigators. Prevalence, awareness, treatment and control of hypertension in the adult Polish population - Multi-center National Population Health Examination Surveys - WOBASZ studies. Arch Med Sci 2018; 14: 951-61.

7. Bielecka-Dabrowa A, Gluba-Brzózka A, Michalska-Kasiczak M, Misztal M, Rysz J, Banach M. The multi-biomarker approach for heart failure in patients with hypertension. Int J Mol Sci 2015; 16: 10715-33.

8. Gakkai NJ. Evidence-based practice guideline for the treatment of CKD. Nihon Jinzo Gakkai Shi 2013; 55: 585-60.

9. Shimamoto K, Ando K, Fujita T, et al., Japanese Society of Hypertension Committee for Guidelines for the Management of Hypertension. The Japanese Society of Hypertension Guidelines for the Management of Hypertension (JSH 2014). Hypertens Res 2014; 37: 253-390.

10. Ito S, Satoh M, Tamaki Y, et al. Safety and efficacy of LCZ696, a first-in-class angiotensin receptor neprilysin inhibitor, in Japanese patients with hypertension and renal dysfunction. Hypertens Res 2015; 38: 269-75.

11. Padmanabhan S, Caulfield M, Dominiczak AF. Genetic and molecular aspects of hypertension. Circ Res 2015; 116: 937-59.

12. Lifton RP, Gharavi AG, Geller DS. Molecular mechanisms of human hypertension. Cell 2001; 104: 545-56.

13. Dominiczak AF, Kuo D. Hypertension: update 2017. Hypertension 2017; 69: 3-4.

14. Ference BA, Julius S, Mahajan N, et al. Clinical effect of naturally random allocation to lower systolic blood pressure beginning before the development of hypertension. Hypertension 2014; 63: 1182-8.

15. Savica V, Bellinghieri G, Kopple JD. The effect of nutrition on blood pressure. Annu Rev Nutr 2010; 30: 365-401.

16. Chan Q, Stamler J, Griep LMO, et al. An update on nutrients and blood pressure. J Atheroscler Thromb 2016; 23: 276-89.

17. Hubert HB, Feinleib M, McNamara PM, et al. Obesity as an independent risk factor for cardiovascular disease: a 26-year follow-up of participants in the Framingham Heart Study. Circulation 1983; 67: 968-77.

18. Huang Z, Willett WC, Manson JE, et al. Body weight, weight change, and risk for hypertension in women. Ann Intern Med 1998; 128: 81-8.

19. Hall JE. The kidney, hypertension, and obesity. Hypertension 2003; 41: 625-33.

20. Garrison RJ, Kannel WB, Stokes J 3rd, et al. Incidence and precursors of hypertension in young adults: the Framingham Offspring Study. Prev Med 1987; 16: 235-51.

21. Forman JP, Stampfer MJ, Curhan GC. Diet and lifestyle risk factors associated with incident hypertension in women. JAMA 2009; 302: 401-11.
22. Klag MJ, He J, Coresh J, et al. The contribution of urinary cations to the blood pressure differences associated with migration. Am J Epidemiol 1995; 142: 295-303.

23. Stamler J. The INTERSALT study: background, methods, findings, and implications. Am J Clin Nutr 1997; 65: 626S-42S.

24. Weinberger MH, Miller JZ, Luft FC, et al. Definitions and characteristics of sodium sensitivity and blood pressure resistance. Hypertension 1986; 8: II127-34.

25. Sanada H, Jones JE, Jose PA. Genetics of salt-sensitive hypertension. Curr Hypertens Rep 2011; 13: 55-66.

26. Carey RM, Schoeffel CD, Gildea JJ, et al. Salt sensitivity of blood pressure is associated with polymorphisms in the sodium-bicarbonate cotransporter. Hypertension 2012; 60: 1359-66.

27. Weinberger MH. Salt sensitivity of blood pressure in humans. Hypertension 1996; 27: 481-90.

28. Khaw KT, Barrett-Connor E. The association between blood pressure, age, and dietary sodium and potassium: a population study. Circulation 1988; 77: 53-61.

29. Lesniak KT, Dubbert PM. Exercise and hypertension. Curr Opin Cardiol 2001; 16: 356-9.

30. Hayashi T, Tsumura K, Suematsu C, et al. Walking to work and the risk for hypertension in men: the Osaka Health Survey. Ann Intern Med 1999; 131: 21-6.

31. Piotrkowska R, Dobosz M, Książek J, Halena G. Social, demographic and clinical characteristics of patients suffering from peripheral vascular disease treated surgically compared to patients treated with endovascular angioplasty. Arch Med Sci Atheroscler Dis 2017; 2: e9-15.

32. Klatsky AL. Alcohol and cardiovascular mortality: common sense and scientific truth. J Am Coll Cardiol 2010; 55: $1336-8$.

33. Calhoun DA, Jones D, Textor S, et al. Resistant hypertension: diagnosis, evaluation, and treatment: a scientific statement from the American Heart Association Professional Education Committee of the Council for High Blood Pressure Research. Hypertension 2008; 51 : 1403-19.

34. Pedrosa RP, Drager LF, Gonzaga CC, et al. Obstructive sleep apnea: the most common secondary cause of hypertension associated with resistant hypertension. Hypertension 2011; 58: 811-7.

35. Grossman E, Messerli FH. Drug-induced hypertension: an unappreciated cause of secondary hypertension. Am J Med 2012; 125: 14-22.

36. Niklas A, Flotyńska A, Puch-Walczak A, et al.; WOBASZ II investigators. Prevalence, awareness, treatment and control of hypertension in the adult Polish population - Multi-center National Population Health Examination Surveys - WOBASZ studies. Arch Med Sci 2018; 14: 951-61.

37. Williams B, Mancia G, Spiering W, et al.; ESC Scientific Document Group. 2018 ESC/ESH Guidelines for the management of arterial hypertension. Eur Heart J 2018; 39: 3021-104.

38. Ruggenenti P, Perna A, Loriga G, et al. Blood-pressure control for renoprotection in patients with non-diabetic chronic renal disease (REIN-2): multicentre, randomised controlled trial. Lancet 2005; 365: 939-46.

39. Wright JT Jr, Bakris G, Greene T, et al. Effect of blood pressure lowering and antihypertensive drug class on progression of hypertensive kidney disease: results from the AASK trial. JAMA 2002; 288: 2421-31.

40. Upadhyay A, Earley A, Haynes SM, et al. Systematic review: blood pressure target in chronic kidney disease 
and proteinuria as an effect modifier. Ann Intern Med 2011; 154: 541-8.

41. Lv J, Ehteshami P, Sarnak MJ, et al. Effects of intensive blood pressure lowering on the progression of chronic kidney disease: a systematic review and meta-analysis. CMAJ 2013; 185: 949-57.

42. Jafar $\mathrm{TH}$, Stark PC, Schmid $\mathrm{CH}$, et al. Progression of chronic kidney disease: the role of blood pressure control, proteinuria, and angiotensin-converting enzyme inhibition: a patient-level meta-analysis. Ann Intern Med 2003; 139: 244-52.

43. Matsushita K, van der Velde M, Astor BC, et al. Association of estimated glomerular filtration rate and albuminuria with all-cause and cardiovascular mortality in general population cohorts: a collaborative meta-analysis. Chronic Kidney Disease Prognosis Consortium. Lancet 2010; 375: 2073-81.

44. James PA, Oparil S, Carter BL, et al. 2014 evidence-based guideline for the management of high blood pressure in adults: report from the panel members appointed to the Eighth Joint National Committee (JNC 8). JAMA 2014; 311: 507-20.

45. National Clinical Guideline Centre (UK). Chronic Kidney Disease (Partial Update): Early Identification and Management of Chronic Kidney Disease in Adults in Primary and Secondary Care. London, UK: National Institute for Health and Care Excellence (UK) 2014.

46. Mancia G, Fagard R, Narkiewicz K, et al. 2013 ESH/ESC guidelines for the management of arterial hypertension: the Task Force for the Management of Arterial Hypertension of the European Society of Hypertension (ESH) and of the European Society of Cardiology (ESC). Eur Heart J 2013; 34: 2159-219.

47. KDIGO clinical practice guideline for the management of blood pressure in chronic kidney disease. Kidney Int Suppl 2012; 2: 337-414.

48. Ninomiya T, Perkovic V, Turnbull F, et al. Blood pressure lowering and major cardiovascular events in people with and without chronic kidney disease: meta-analysis of randomised controlled trials. BMJ 2013; 347: f5680.

49. Kovesdy CP, Alrifai A, Gosmanova EO, et al. Age and outcomes associated with BP in patients with incident CKD. Clin J Am Soc Nephrol 2016; 11: 821-31.

50. Weiss JW, Peters D, Yang X, et al. Systolic BP and mortality in older adults with CKD. Clin J Am Soc Nephrol 2015; 10: 1553-9.

51. Kalaitzidis RG, Karasavvidou D, Siamopoulos KC. Hypertension and chronic kidney disease: pathophysiology and management strategies. BANTAO J 2011; 9: 49-58.

52. Sarafidis PA, Sharpe CC, Wood E, et al. Prevalence, patterns of treatment, and control of hypertension in pre-dialysis patients with chronic kidney disease. Nephron Clin Pract 2012; 120: c147-55.

53. Charra B. Fluid balance, dry weight, and blood pressure in dialysis. Hemodial Int 2007; 11: 21-31.

54. Klein IH, Ligtenberg G, Neumann J, Oey PL, Koomans HA, Blankestijn PJ. Sympathetic nerve activity is inappropriately increased in chronic renal disease. J Am Soc Nephrol 2003; 14: 3239-44.

55. Rüster C, Wolf G. Renin-angiotensin-aldosterone system and progression of renal disease. J Am Soc Nephrol 2006; 17: 2985-91.

56. Fliser D, Kronenberg F, Kielstein JT, et al. Asymmetric dimethylarginine and progression of chronic kidney disease: the mild to moderate kidney disease study. J Am Soc Nephrol 2005; 16: 2456-61.
57. LambersHeerspink HJ, Brantsma AH, de Zeeuw D, et al. Albuminuria assessed from first-morning-void urine samples versus 24-hour urine collections as a predictor of cardiovascular morbidity and mortality. Am J Epidemiol 2008; 168: 897-905.

58. Esnault VLM, Brown EA, Apetrei E, et al. The effects of amlodipine and enalapril on renal function in adults with hypertension and nondiabetic nephropathies: a 3-year, randomized, multicenter, double-blind, placebo-controlled study. Clin Ther 2008; 30: 482-98.

59. Giatras I, Lau J, Levey AS. Effect of angiotensin-converting enzyme inhibitors on the progression of nondiabetic renal disease: a meta-analysis of randomized trials. Angiotensin-Converting-Enzyme Inhibition and Progressive Renal Disease Study Group. Ann Intern Med 1997; 127: 337-45.

60. Yusuf S, Teo KK, Pogue J, et al. Telmisartan, ramipril, or both in patients at high risk for vascular events. ONTARGET Investigators. N Engl J Med 2008; 358: 1547-59.

61. Fried LF, Emanuele N, Zhang JH, et al. Combined angiotensin inhibition for the treatment of diabetic nephropathy. N Engl J Med 2013; 369: 1892-903.

62. Parving HH, Brenner BM, McMurray JJV, et al. Cardiorenal end points in a trial of aliskiren for type 2 diabetes. N Engl J Med 2012; 367: 2204-13.

63. Sica DA, Gehr TW. Calcium-channel blockers and endstage renal disease: pharmacokinetic and pharmacodynamics considerations. Curr Opin Nephrol Hypertens 2003; 12: 123-31.

64. Bakris GL, Mangrum A, Copley JB, et al. Effect of calcium channel or beta-blockade on the progression of diabetic nephropathy in African Americans. Hypertension 1997; 29: 744-50.

65. Bakris GL, Weir MR, Shanifar S, et al. Effects of blood pressure level on progression of diabetic nephropathy: results from the RENAAL study. Arch Intern Med 2003; 163: 1555-65.

66. Bakris GL, Weir MR, Secic M, et al. Differential effects of calcium antagonist subclasses on markers of nephropathy progression Kidney Int 2004; 65: 1991-2002.

67. Jamerson K, Weber MA, Bakris GL, et al. Benazepril plus amlodipine or hydrochlorothiazide for hypertension in high-risk patients. N Engl J Med 2008; 359: 2417-28.

68. Goch A, Banach M, Mikhailidis DP, Rysz J, Goch JH. Endothelial dysfunction in patients with noncomplicated and complicated hypertension. Clin Exp Hypertens 2009; 31: 20-30.

69. Feldman DL, Jin L, Xuan $H$, et al. Effects of aliskiren on blood pressure, albuminuria, and (pro)renin receptor expression in diabetic TG(mRen-2)27 rats. Hypertension 2008; 52: 130-6.

70. Kuhnast S, van der Hoorn JW, van den Hoek AM, et al. Aliskiren inhibits atherosclerosis development and improves plaque stability in APOE*3Leiden. CETP transgenic mice with or without treatment with atorvastatin. J Hypertens 2012; 30: 107-16.

71. Parving HH, Persson F, Lewis JB, et al. Aliskiren combined with losartan in type 2 diabetes and nephropathy. N Engl J Med 2008; 358: 2433-46.

72. Sidik NP, Solomon SD, Latini R, et al. Effect of aliskiren in patients with heart failure according to background dose of ACE inhibitor: a retrospective analysis of the Aliskiren Observation of Heart Failure Treatment (ALOFT) trial. Cardiovasc Drugs Ther 2011; 25: 315-21.

73. Goddard J, Johnston NR, Hand MF, et al. Endothelin-A receptor antagonism reduces blood pressure and 
increases renal blood flow in hypertensive patients with chronic renal failure: a comparison of selective and combined endothelin receptor blockade. Circulation 2004; 109: 1186-93.

74. Goddard J, Eckhart C, Johnston NR, et al. Endothelin A receptor antagonism and angiotensin-converting enzyme inhibition are synergistic via an endothelin B receptor-mediated and nitric oxide-dependent mechanism. J Am Soc Nephrol 2004; 15: 2601-10.

75. Weber MA, Black H, Bakris G, et al. A selective endothelin-receptor antagonist to reduce blood pressure in patients with treatment-resistant hypertension: a randomised, double-blind, placebo-controlled trial. Lancet 2009; 374: 1423-31.

76. Wenzel RR, Littke T, Kuranoff S, et al. Avosentan reduces albumin excretion in diabetics with macroalbuminuria. J Am Soc Nephrol 2009; 20: 655-64.

77. Ettehad D, Emdin CA, Kiran A, et al. Blood pressure lowering for prevention of cardiovascular disease and death: a systematic review and meta-analysis. Lancet 2016; 387: 957-67.

78. Thomopoulos C, Parati G, Zanchetti A. Effects of blood pressure lowering on outcome incidence in hypertension: effects of more vs. less intensive blood pressure lowering and different achieved blood pressure levels - updated overview and meta-analyses of randomized trials. J Hypertens 2016; 34: 613-22.

79. Xie X, Atkins E, Lv J, et al. Effects of intensive blood pressure lowering on cardiovascular and renal outcomes: updated systematic review and meta-analysis. Lancet 2016; 387: 435-43.

80. Nerenberg KA, Zarnke KB, Leung AA, et al. Hypertension Canada's 2018 guidelines for diagnosis, risk assessment, prevention, and treatment of hypertension in adults and children. Can J Cardiol 2018; 34: 506-25.

81. Weber MA, Schiffrin EL, White WB, et al. Clinical practice guidelines for the management of hypertension in the community: a statement by the American Society of Hypertension and the International Society of Hypertension. J Clin Hyperten 2014; 16: 14-26.

82. Mancia G, Fagard R, Narkiewicz K, et al. 2013 ESH/ESC guidelines for the management of arterial hypertension: the Task Force for the Management of Arterial Hypertension of the European Society of Hypertension (ESH) and of the European Society of Cardiology (ESC). Eur Heart J 2013; 34: 2159-219.

83. National Institute for Health and Care Excellence (NICE). Hypertension in adults: diagnosis and management. Clinical guideline CG127. http://www.nice.org. uk/guidance/CG127. Accessed October 21, 2018.

84. Chobanian AV, Bakris GL, Black HR, et al. The seventh report of the Joint National Committee on Prevention, Detection, Evaluation, and Treatment of High Blood Pressure: the JNC 7 report. JAMA 2003; 289: 2560-71.

85. Carrero JJ, Cozzolino M. Nutritional therapy, phosphate control and renal protection. Nephron Clin Pract 2014; 126: 1-7.

86. Rysz J, Franczyk B, Ciałkowska-Rysz A, Gluba-Brzózka A. The effect of diet on the survival of patients with chronic kidney disease. Nutrients 2017; 9: 495.

87. Sacks FM, Svetkey LP, Vollmer WM, et al. Effects on blood pressure of reduced dietary sodium and the Dietary Approaches to Stop Hypertension (DASH) diet. DASH-Sodium Collaborative Research Group. N Engl J Med 2001; 344: 3-10.

88. SchwingshackI L, Hoffmann G. Diet quality as assessed by the Healthy Eating Index, the Alternate Healthy Eat- ing Index, the Dietary Approaches to Stop Hypertension score, and health outcomes: a systematic review and meta-analysis of cohort studies. J Acad Nutr Diet 2015; 115: 780-800.

89. Tyson CC, Lin PH, Corsino L, et al. Short-term effects of the DASH diet in adults with moderate chronic kidney disease: a pilot feeding study. Clin Kidney J 2016; 9: 592-8.

90. Rebholz CM, Crews DC, Grams ME, et al. DASH (dietary approaches to stop hypertension) diet and risk of subsequent kidney disease. Am J Kidney Dis 2016; 68: 853-61.

91. Carrero JJ, Cozzolino M. Nutritional therapy, phosphate control and renal protection. Nephron Clin Pract 2014; 126: 1-7.

92. Krasinska B, Osińska A, Osinski M, et al. Standardised tomato extract as an alternative to acetylsalicylic acid in patients with primary hypertension and high cardiovascular risk - a randomised, controlled trial. Arch Med Sci 2018; 14: 773-80.

93. Staffileno BA, Minnick A, Coke LA, Hollenberg SM. Blood pressure responses to lifestyle physical activity among young, hypertension-prone African-American women. J Cardiovasc Nurs 2007; 22: 107-17.

94. Diaz KM, Booth JN III, Seals SR, et al. Physical activity and incident hypertension in African Americans: the Jackson Heart Study. Hypertension 2017; 69: 421-7.

95. Börjesson M, Onerup A, Lundqvist S, Dahlöf B. Physical activity and exercise lower blood pressure in individuals with hypertension: narrative review of $27 \mathrm{RCTs}$. $\mathrm{Br}$ J Sports Med 2016; 50: 356-61.

96. Cavelaars $\mathrm{M}$, Tulen $\mathrm{JH}$, van Bemmel JH, ter Borg MJ, Mulder PG, van den Meiracker AH. Determinants of ambulatory blood pressure response to physical activity. J Hypertens 2002; 20: 2009-15.

97. Cernes R, Zimlichman R. RESPeRATE: the role of paced breathing in hypertension treatment. JASH 2015; 9: 38-47.

98. Wakabayashi I. Influence of gender on the association of alcohol drinking with blood pressure. Am J Hypertens 2008; 21: 1310-7.

99. Freeman AJ, Vinh A, Widdop RE. Novel approaches for treating hypertension. F1000Research 2017; 6: 80.

100. Judd EK, Oparil S. Novel strategies for treatment of resistant hypertension. Kidney Int Suppl 2013; 3: 35763.

101. Grassi G, Quarti-Trevano F, Seravalle G, et al. Early sympathetic activation in the initial clinical stages of chronic renal failure. Hypertension 2011; 57: 846-51.

102. Zoccali C, Mallamaci F, Parlongo S, et al. Plasma norepinephrine predicts survival and incident cardiovascular events in patients with end-stage renal disease. Circulation 2002; 105: 1354-9.

103. Schlaich MP, Socratous F, Hennebry S, et al. Sympathetic activation in chronic renal failure. J Am Soc Nephrol 2009; 20: 933-9.

104. Hering D, Mahfoud F, Walton AS, et al. Renal denervation in moderate to severe CKD. J Am Soc Nephrol 2012; 23: 1250-7.

105. Schlaich MP, Sobotka PA, Krum H, et al. Renal denervation as a therapeutic approach for hypertension: novel implications for an old concept. Hypertension 2009; 54: 1195-201.

106. Sobotka PA, Mahfoud F, Schlaich MP, et al. Sympatho-renal axis in chronic disease. Clin Res Cardiol 2011; 100: 1049-57. 
107. Esler MD, Böhm M, Sievert H, et al. Catheter-based renal denervation for treatment of patients with treatment-resistant hypertension: 36 month results from the SYMPLICITY HTN-2 randomized clinical trial. Eur Heart J 2014; 35: 1752-9.

108. Krum H, Schlaich MP, Sobotka PA, et al. Percutaneous renal denervation in patients with treatment-resistant hypertension: final 3-year report of the Symplicity HTN-1 study. Lancet 2014; 383: 622-9.

109. Bhatt DL, Kandzari DE, O’Neill WW, et al.; SYMPLICITY HTN-3 Investigators. A controlled trial of renal denervation for resistant hypertension. N Engl J Med 2014; 370: 1393-401.

110. Sega R, Facchetti R, Bombelli M, et al. Prognostic value of ambulatory and home blood pressures compared with office blood pressure in the general population: follow-up results from the Pressioni Arteriose Monitoratee Loro Associazioni (PAMELA) study. Circulation 2005; 111: 1777-83.

111. Ditting T, Hilgers KF, Stetter A, Linz P, Schönweiss C, Veelken R. Renal sympathetic nerves modulate erythropoietin plasma levels after transient hemorrhage in rats. Am J Physiol Renal Physiol 2007; 293: F1099-106.

112. Marchais SJ, Guerin AP, Pannier BM, Levy BI, Safar ME, London GM. Wave reflections and cardiac hypertrophy in chronic uremia. Influence of body size. Hypertension 1993; 22: 876-83

113. Benigni A, Zoja C, Zatelli C, et al. Vasopeptidase inhibitor restores the balance of vasoactive hormones in progressive nephropathy. Kidney Int 2004; 66: 1959-65.

114. Schlaich MP, Bart B, Hering D, et al. Feasibility of catheter-based renal nerve ablation and effects on sympathetic nerve activity and blood pressure in patients with end-stage renal disease. Int J Cardiol 2013; 168: 2214-20.

115. Kostis JB, Packer M, Black HR, et al. Omapatrilat and enalapril in patients with hypertension: the Omapatrilat Cardiovascular Treatment vs. Enalapril (OCTAVE) trial. Am J Hypertens 2004; 17: 103-11.

116. Cao Z, Burrell LM, Tikkanen I, Bonnet F, Cooper ME, Gilbert RE. Vasopeptidase inhibition attenuates the progression of renal injury in subtotal nephrectomizedrats. Kidney Int 2001; 60: 715-21.

117. Packer M, Califf RM, Konstam MA, et al. Comparison of omapatrilat and enalapril in patients with chronic heart failure: the Omapatrilat Versus Enalapril Randomized Trial of Utility in Reducing Events (OVERTURE) Circulation 2002; 106: 920-6.

118. Paulis L, Rajkovicova R, Simko F. New developments in the pharmacological treatment of hypertension: deadend or a glimmer at the horizon? Curr Hypertens Rep 2015; $17: 557$.

119. Ruilope LM, Dukat A, Böhm M, et al. Blood-pressure reduction with LCZ696, a novel dual-acting inhibitor of the angiotensin II receptor and neprilysin: a randomised, double-blind, placebo-controlled, active comparator study. Lancet 2010; 375: 1255-66.

120. Martínez-Castelao A, Górriz JL, Portolés JM, et al. Baseline characteristics of patients with chronic kidney disease stage 3 and stage 4 in Spain: the MERENA observational cohort study. BMC Nephrol 2011; 12: 53.

121. Peralta CA, Hicks LS, Chertow GM, et al. Control of hypertension in adults with chronic kidney disease in the United States. Hypertension 2005; 45: 1119-24.

122. Prøsch LK, Saelen MG, Gudmundsdottir H, et al. Blood pressure control is hard to achieve in patients with chronic renal failure: results from a survey of renal units in Norway. Scand J Urol Nephrol 2005; 39: 242-8.

123.http://www.harp3trial.org; Accessed on $2^{\text {nd }}$ February 2018.

124. Gluba-Brzózka A, Franczyk B, Olszewski R, Banach M, Rysz J. Personalized medicine: new perspectives for the diagnosis and the treatment of renal diseases. Int J Mol Sci 2017; 18: pii: E1248.

125. Bielecka-Dabrowa A, Sakowicz A, Pietrucha T, et al. The profile of selected single nucleotide polymorphisms in patients with hypertension and heart failure with preserved and mid-range ejection fraction. Sci Rep 2017 7: 8974.

126. Rysz J, Franczyk B, Banach M, Gluba-Brzozka A. Hypertension - current natural strategies to lower blood pressure. Curr Pharm Des 2017; 23: 2453-61.

127. Yalcin S, Bayram F, Erdamar S, Kucuk O, Oruc N, Coker A Gastroenteropancreatic neuroendocrine tumors: recommendations of Turkish multidisciplinary neuroendocrine tumor study group on diagnosis, treatment and follow-up. Arch Med Sci 2017; 13: 271-82. 